\title{
Diagramming Mythical Reality: A Qualitative Analysis of Middle Children's Identity Check, Phenomenology
}

\author{
Monaliza P. Cayatoc MAG RGC, Joy Anne P. Dela Cruz, Jewel Betina P. Baluyut, \\ Keight Dainiel G. Comia, Justin Charles D. Pe, Kyle Eric C. Ruben, Richele Marianne J. Capili, \\ Kiana Vanessa C. Ruiz, Yasmin G. Ulod
}

\begin{abstract}
Background: Middle children are often perceived to face hardships that directly affect their upbringing. They are known to be excluded frequently or even neglected by their own family. This phenomenon is known as middle child syndrome. This study focuses on an in-depth analysis of middle children's experiences to further understand the factors that majorly contribute to their identity formation. Method: This qualitative paper utilized a phenomenological design to understand the participant's unique experiences. Data were gathered through a semi-structured interview which were then used to create four major themes. These themes and their corresponding sub themes were assembled to create the study's simulacrum. The aim of the study is to understand the middle children's identity formation pertaining to the central question: "What are the common life challenges experienced by a middle child?" Findings: This study shows that there were different traits which middle children have developed which are expressed in the themes: maturity, responsibility, and affinity.. Conclusion: The research concludes that middle children's identity formation is directly correlated to how their family treats them.
\end{abstract}

Index Terms - Middle Child Syndrome, Birth Order, Sibling Relationship, Familial Relations, Identity Formation, Child Upbringing, Maturity, Responsibility, Affinity

Monaliza P. Cayatoc, MAG, RGC, Research Capstone Project/ Research Development Accreditation and Publication Office/ Philippine School Doha/ Doha, Qatar

Joy Anne P. Dela Cruz, Research Capstone Project/ Research Development Accreditation and Publication Office/ Philippine School Doha/ Doha, Qatar

Jewel Betina P. Baluyut, Research Capstone Project/ Research Development Accreditation and Publication Office/ Philippine School Doha/ Doha, Qatar

Keight Dainiel G. Comia, Research Capstone Project/ Research Development Accreditation and Publication Office/ Philippine School Doha/ Doha, Qatar

Justin Charles D. Pe, Research Capstone Project/ Research Development Accreditation and Publication Office/ Philippine School Doha/ Doha, Qatar

Kyle Eric C. Ruben, Research Capstone Project/ Research Development Accreditation and Publication Office/ Philippine School Doha/ Doha, Qatar

Richele Marianne J. Capili, Research Capstone Project/ Research Development Accreditation and Publication Office/ Philippine School Doha/ Doha, Qatar

Kiana Vanessa C. Ruiz, Research Capstone Project/ Research Development Accreditation and Publication Office/ Philippine School Doha/ Doha, Qatar

Yasmin G. Ulod, Research Capstone Project/ Research Development Accreditation and Publication Office/ Philippine School Doha/ Doha, Qatar

\section{INTRODUCTION}

Having an exceptional family orientation is crucial to everybody living in a Filipino household. Families are regarded as the foundation of the social lives of many Filipinos, for their tight knit bonds are not only among the members of the immediate family, but extends to other family members (de Guzman, 2011). A harmonious Filipino family is not possible without filial piety. Filial piety is observed by every family member, most especially the young ones for they serve as the faces of the families and are responsible to continue whatever legacy their parents left behind (Chara, 2016). It is important for members of the family to do their duties, fulfill their responsibilities, and accomplish their tasks in order to respect the other members and to ensure harmony among family members.

Not all families, however, display close family ties; contrary to what is expected from a Filipino household. Some family members may feel that they are left out or taken for granted. This feeling of unworthiness may stem from the fact that their accomplishments, personality, and talents may be overshadowed by other family members. At the same time, they might find it hard to create and even maintain an intimate and close relationship with people who often devalue their existence.

Alfred Adler, a psychotherapist and the founder of the school of individual psychology, developed a theory that states that the birth order between the siblings have a profound and significant effect on the development of personality and character (Hartmann \& Goudarzi, 2019). Part of this theory are the specific characteristics of middle children. They differ from the oldest and youngest by being even-tempered, but most of the time, they are said to have trouble fitting in because they are basically in between two other human beings (Werner, 2013). Since the eldest feel powerful in a way that everything he or she says goes, the eldest does a lot more tasks and is given more responsibilities than the youngest, which is generalized as the pampered and spoiled sibling in the family; leaving the middle child to feel that they have no clear role or status in the family (Combs-Draughn, 2016). They are theorized to feel "as if they are overshadowed by their siblings, and with that they develop characteristics that psychologists call as the features of 'Middle Child Syndrome' (Arora, 2019). 
The middle child syndrome is a belief that middle children are excluded, ignored, or even outright neglected because of their birth order (Adler, n.d.). Studies show that many middle children share common characteristics with each other, thus common ideas are formed around the middle children (Griffin, 2012). They are relatively quiet and shy, for they feel as if they are dulled down by their siblings' personalities. They usually have trouble feeling equal to their siblings, which often leads to them having to compete with both the younger and older sibling just to garner parental and general attention (Werner, 2013). They generally feel that they are not the favorite child of the family, making them resentful towards the other siblings because they have been somewhat ignored because of them (Dodgson, 2017).

This research aims to qualitatively analyze the lived experiences of the Filipino middle children living in Qatar. It studies the different personalities, attributes, and qualities that form the different yet unique characters of middle children. With Adler's theory as the theoretical lens, the research may provide a clear understanding and deconstruct the biases surrounding middle children. This study bridges the gap between studying middle children from afar and basing the conclusions through observations, and being able to talk to them and analyze their actual personalities.

This study takes into account the perspectives of Filipino middle children in Qatar. It spotlights the different identities of each middle child and what they go through in their daily lives. This study focuses on answering the central question, which tackles the common challenges that a middle child lives through every day. The formulated sub questions emphasize the coping tactics of middle children. It talks about how they face these challenges and how they adjust to these challenges. It also emphasizes the common sources of stress for these middle children, particularly what makes them feel tense within their family and in public. 31 developmental questions have been constructed to be answered by the interviewees. These in-depth questions were formulated as an effort to paint the world from the view of the participants.

This study proves that middle children do encounter challenges on a day to day basis. Challenges such as: getting into arguments between siblings, gaining the attention of their parents, and having trouble socializing with other people. The perception of the world being secretive with their thoughts, and about middle children is said to be inaccurate. With the responses of the participants, the researchers were able to organize the gathered data through an emic-etic transcription. Afterwards, the transcribed data were analyzed in order to create themes through a dendrogram. The researchers were able to create the following major themes: maturity, affinity, and responsibility. These themes and their corresponding sub themes were gathered to create the simulacrum.

Middle children are perceived to be the timid, overshadowed, and peacemakers in the family. Based on the responses of the participants, these perceptions are proven to be true to the majority but there are also a few participants who describe themselves as extroverted, appreciated, and not the peacemakers of the family. The participants also feel that they do not need to get their parents' attention, though some would strive to be great in terms of academics and extracurricular activities in order to garner attention. The consensus that middle children are more reserved, less extroverted, and more likely to face difficulties in socializing with other people including their parents are true to the majority of the participants.

\section{RESEARCH DESIGN}

This study is qualitative in nature and uses a phenomenological design. Qualitative research involves collecting and analyzing non-numerical data (e.g., text, video, or audio) to understand concepts, opinions, or experiences. It can be used to gather in-depth insights into a problem or generate new ideas for research (Bhandari, 2020). Qualitative research is multimethod in focus, involving an interpretive, naturalistic approach to its subject matter. This means that qualitative researchers study things in their natural settings, attempting to make sense of, or interpret, phenomena in terms of the meanings people bring to them (Denzin \& Lincoln, 1994 as cited by McLeod, 2019).

A phenomenological research design is a study that attempts to understand people's perceptions and understanding of a particular phenomenon (Pathak, 2017). The main purposes of phenomenological research are to seek reality from individuals' narratives of their experiences and feelings, and to produce in-depth descriptions of the phenomenon (Yüksel \& Yildırım, 2015). The purpose of the phenomenological approach is to illuminate the specific, to identify phenomena through how they are perceived by the actors in a situation. In the human sphere this normally translates into gathering 'deep' information and perceptions through inductive, qualitative methods such as interviews, discussions and participant observation, and representing it from the perspective of the research participant(s). Phenomenology is concerned with the study of experience from the perspective of the individual, 'bracketing' taken-for-granted assumptions and usual ways of perceiving (Lester, 1999).

Using a qualitative phenomenological research approach allowed the researchers to analyze the life experiences of middle children regarding their identity. Phenomenology is an approach to qualitative research that focuses on the commonality of a lived experience within a particular group. Through this process the researcher may construct the universal meaning of the event, situation or experience and arrive at a more profound understanding of the phenomenon (Creswell, 2013 as cited by Mustafa, 2021).

An inductive approach is concerned with the generation of new theory emerging from data. The aim is to generate a new theory based on the data (Gabriel, 2013). Inductive reasoning, or inductive logic, is a type of reasoning that involves drawing a general conclusion from a set of specific observations (MasterClass, 2020). 
This study conducted interviews in order to attain the necessary information needed for the Introduction, Methods, Results, and Discussion (IMRAD) paper. The participants were interviewed based on the 31 developmental questions which were generated by the researchers and approved by the validators. Thematic data analysis was used to come up with a new theory based on the responses of the participants. Inductive reasoning, or inductive logic, is a type of reasoning that involves drawing a general conclusion from a set of specific observations (Caulfield, 2020).

The strategy employed was implemented to explore the characteristics that are known as 'Middle Child Syndrome.' Comprehensive interviews were done to gather insights about the participants' experiences brought about by their birth order. The data collected was qualitative. The analysis included an attempt to connect responses with specific themes regarding the experiences of the participants.

\section{A. Research Locale and Sample Data Collection and Ethical Consideration}

The participants in this study were selected using the following criteria: (1) the participant has to be a middle child indicatively, they have to be in the middle of the birth order among his/her siblings. (2) the participant should be a Filipino citizen residing in the State of Qatar. (3) the participant must currently be enrolled as a Senior High School student. Among the participants, six come from a family with three children while one comes from a family with five children giving this study a total number of seven participants. The sample size used in qualitative research methods is often smaller than that used in quantitative research methods. This is because qualitative research methods are often concerned with garnering an in-depth understanding of a phenomenon (Dworkin, 2012).

The study site of the research paper is in Philippine School Doha (PSD) in Doha, Qatar. The school was established in October 1992 in order to provide the children of the Filipino community in Doha, Qatar their educational needs with the support of the Philippine Embassy.

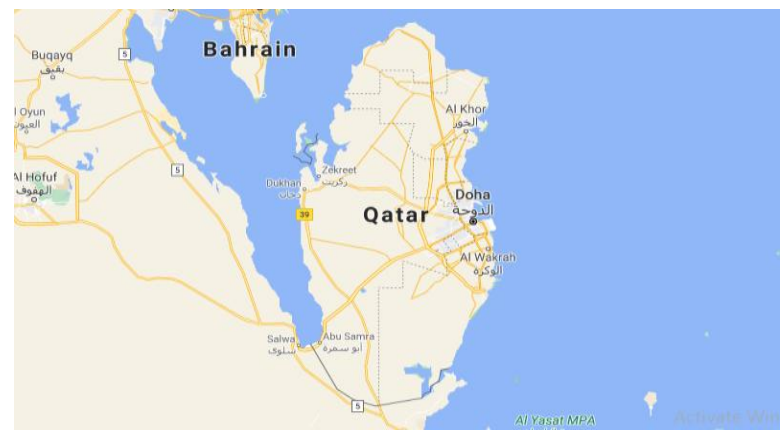

Figure 1: Map of The State of Qatar

Source: Google Maps https://www.google.com/maps

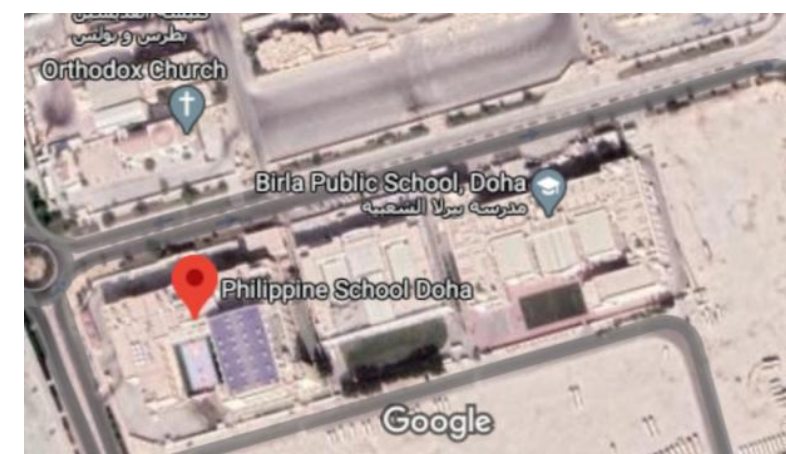

Figure 2: Location of Philippine School Doha at Al-Messiah, Doha, Qatar

Source: Google Maps https://www.google.com/maps

\section{B. Data Collection and Ethical Consideration}

The researchers made use of a two-part instrument for data collection. The first part of data gathering made use of a 'robotfoto' to establish the demographic profile of the respondents (de Guzman et al., 2009). The participants were given a robotfoto before the interview in order for the researchers to collect the needed personal information of the participants. In this study, the robotfoto consists of the name, age, birth year, gender, contact number, e-mail, address, and the gender and birth year of the participants' siblings according to birth order.

An interview guide was created based on the central and specific questions. Validation of interview questions was performed to ensure its validity. After the robotfoto, a 31-item semi-structured interview was conducted through Zoom meetings which were recorded with the permission of the participants through a consent form. If the interviews are recorded, everyone involved in the project can listen first-hand - to participant answers, at their leisure. This allows team members to hear for themselves such things as whether certain questions were misunderstood, or if some aspect of the question flow proved frustrating for participants (CSR- Center for Strategy Research Boston, 2006). Before the interview was conducted, the participants were guaranteed that their identity is kept confidential at all times and only the researchers and their adviser will know their identity.

\section{Data Analysis}

Data analysis in qualitative research is defined as the process of systematically searching and arranging the interview transcripts, observation notes, or other non-textual materials that the researcher accumulates to increase the understanding of the phenomenon (Wong, 2008).

In order for the analysis to be successful, it needs to follow certain steps which are the following; (1) Transcription of the data in the recording into text; (2) Transcription of the participant's own words also known as emic transcriptions into the researcher's understanding known as etic transcriptions; (3) Compilation of the emic responses of the participants through cool analysis; (4) Identification of similar ideas in the responses of participants in order to form thought units; (5) Generation of themes from the responses 
through the use of dendrogram; (6) Creation of simulacrum will help the readers to understand the topic of the paper.

The second level of data analysis was acquired through the use of the related literature and studies. The related literature and studies were presented by the researchers to support the responses of the participants which were expounded by the researchers.

\section{RESULTS}

This phenomenological attempt discloses the factors of middle children's identity check to answer the question; What are the common life challenges experienced by a middle child? Based on the answers of the respondents we are able to come up with three factors that are conducive to the formation of identity. Maturity includes an individual's need to think more adult like at a young age in order to be a better role model to their siblings that are younger. Responsibility shows that due to how each middle child has more tasks assigned to them and less attention given it really has an impact on a child's way of living. Affinity exhibits the relationship of the individual to their other family members. These conducive factors are what affects a middle child's identity.

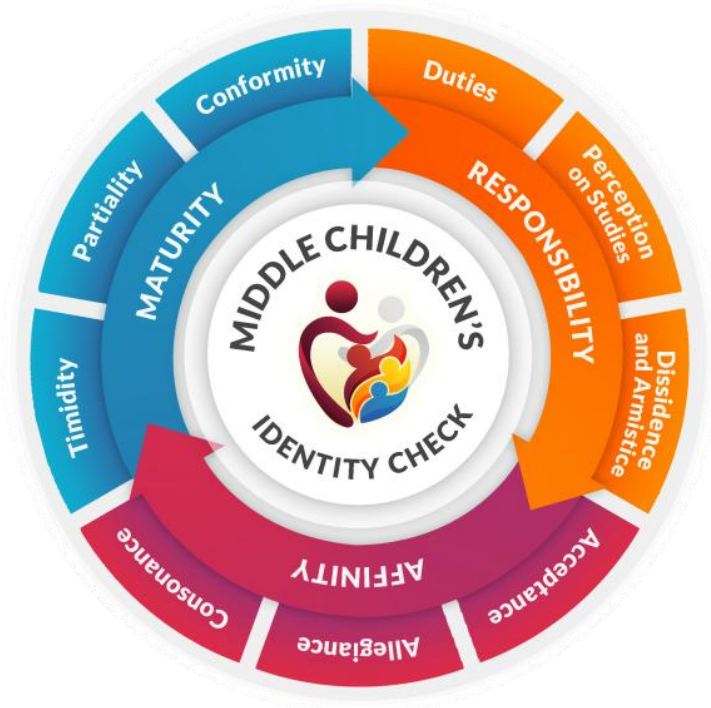

Figure 3: Simulacrum

The figure displays the contributive factors of middle children's identity formation. The arrows show how the three factors are all interconnected and all contributive to the formation identity such as maturity, responsibility and affinity factors.

\section{A. Maturity}

Maturity is a dynamic process in a child's growth. Each child is taught by their parents in preparation for adulthood so they can be capable and more than willing of acting on their own. Their childhood experiences are not as different from the respondents, especially since many participants have particularly expressed their shyness. It was not very easy for them to socialize with other people. Timidity was observed as their responses were interpreted below:

"Our childhood experiences were not so different from each other; it was just that I was shyer than my siblings." $(P 8)$

"It is not easy for me since I see myself as a shy person, at first. But if you get to know me, I am quite loud and playful." (P1)

Hence, they claimed that they do not need to get their parents' attention since they prefer to be independent so they can learn how to do things by themselves. Attention from their parents was not in demand. Middle children are presumed to be mature as they show their resilience after partiality whenever their parents divide their attention among their siblings.

"I don't always need to get my parents' attention because I like to see myself being independent.” (P6)

"No, because I know I can do something independently and I need to be more responsible of myself so I do not want my parents to pay attention to me at all times because I need to know how to do things by myself." (P4)

Nonetheless, their childhood experiences were not too different and complicated from other children. Their birth order does not affect their well-being thoroughly. They also made mention that the perceptions and assumptions created towards middle children are inaccurate. They are not treated differently nor pitied at all.

"My childhood was not really that different from others but considering our status I can say that I had much more to think back then I had to think more about the future and how I can be of help to my parents and my siblings." (P4)

"I think it is not accurate. Most people think that the middle child does not get the attention, but I think they receive the same attention as the other siblings. "(P6)

Based on their statements, middle children have the willingness to grow and be on their own. Their childhood may not be as different from others although they may have expressed their timidity in some statements. Discovering and developing themselves were also evident among the respondents. Communicating was not one of their strengths although maturity has been evident as they thoroughly explain their similar experiences. Birth order was not too much of a problem for them. In fact, they believed that these stereotypes were typically untrue.

\section{B. Responsibility}

In a family, it is normal for each member to have their own tasks and responsibilities in their home, some of which include their perception on studies, their duties, and them 
being there for dissidence and armistice. Meanwhile, in some homes, these tasks are not distributed equally and most of the time, the middle children are given more tasks compared to their older and younger siblings. This is backed up by the response of our respondents.

"Not exactly, I think I get more since my sister is busy and she is not with us and my little brother is younger I guess and I was left in the middle to do like the work and my mom usually like relies on me to like uh do the chores and stuff and I do not really complain that much." (P4)

"I do most of the tasks in this house. I delegate tasks but they refuse to do them anyways so I end up doing them." (P7)

Middle children are also given less attention than their siblings which led them to use their academics as a bridge to catch their parent's attention as stated by our respondents.

"I think it's mostly about my academics, I want my parent's attention when I receive high grades in school." (P8)

Dissidence can't be avoided especially between siblings which cause middle children to be the mediator and the peacemaker for their siblings as expressed,

"Among us siblings, I am the peacemaker since my older and younger brother do things that can start an argument." (P1)

"I'm the peacemaker between me and my siblings, the ones who start the fight are both my brother and sister because they're usually the one who has a need or want." (P8)

Responsibilities truly have a big impact on how middle children feel, act, and live their lives. The responsibilities of middle children do not only focus on themselves but reach out to the other members of their family.

\section{Affinity}

The relationship of the middle child to his or her parents and siblings, and the degree of closeness between each member of the family are crucial in shaping his or her character and attitude. Within a home that shelters 3 or more siblings for many years, unique ways have been used to solve problems such as this respondent. She stated,

"Yes, they were there many times that we picked on each other, and they picked on me, but we do not take it seriously, so we would usually just laugh it out." (P8)

An inevitable factor that causes problems within a family is favoritism. However, these respondents do not particularly agree with the consensus that there is such thing from within the family, with statements such as:

\section{"I am treated the same way as my siblings" (P2)}

"In terms of our parents, I would say I am treated equally with my siblings but, when it comes to other people they notice my sister and brother more." (P8)

The bond between siblings is vital to them for it serves a significant contribution to their lives. Sibling bonds are some of the strongest connections we can make in our lives, emotional attachments that happen early and are rooted deeply in our development. Siblings help us to learn crucial skills to navigate relationships, find a sense of identity, and understand how to create attachment to others. Most of the respondents resonate with their siblings, such as these respondents who said,

"I do not feel left out whenever I am with my family because we tend to do things a lot and bond together. "(P1)

"I have never felt left out or if I did it was really rare because I don't usually get left out." (P8)

Of course, it is not only the relationship between siblings that are important. The relationship between the parents and the child are equally or even more important. Most of the respondents are very close to their parents, like this respondent, who openly expressed,

"As for my parents, we are actually close with each other. I open up things to them and that there is no gap between our relationship." (P1)

The bonds between each member of the family impact the lives of middle children, for they get to live a life that is not determined by the perception of society towards them. They get to feel safe, secure, and most importantly, they get to feel loved unconditionally.

Undeniably, the growth of a middle child, their experiences with dealing with responsibilities, and the relationship with their parents are siblings, are important factors that impact their lives as middle children, and are also important factors that help disprove the stereotype surrounding them.

\section{DISCUSSION}

Bringing to light the different experiences of the middle children in Philippine School Doha, this phenomenological study emphasizes the everyday experiences that they go through, which contributes to their growth that leads to the formation of their self-identity. The unique stories of the middle children uncovered three factors that affect their identity formation. Maturity; uncovers their intellectual development, Responsibility; exhibits the effects of the different responsibilities on their self-formation and Affinity ; shows their relationship with their family. Middle children experience these factors daily. As middle children and students, they encounter unforeseeable experiences every day that contribute to their identity formation. 


\section{A. Conformity}

There are many stereotypes amongst middle children in the family. Children in the middle tend to be neglected and frustrated for various reasons. This includes being sandwiched between the eldest and the youngest (Pant, K., \& Singh, R., 2016). In most cases, middle-borns do not have the rights of the oldest and the privileges of the youngest thus making it difficult for them to find their own niche and voice in the family. This propels them to exhibit different behaviors as they grow up. Some suggest that middle-born children are more rebellious, less conscientious, less religious, and demonstrate lower school performance than their firstborn siblings (Eickstein, 2000; Sarolglou \& Fiasse, 2003). These children tend to feel their lives are overly scrutinized and look outside the family for their own autonomy. The middle child reacts by acting out as a "rebel". Middle-children are believed to be very envious and try to escape their roles (Jimoh, A.M., 2019). Having no role model to look up to, middle children deviate in terms of their behaviors compared to their siblings. Manifesting different behaviors allows them to get the attention of their parents and develop a sense of self-identity. There is a lack of concrete evidence that proves that birth order necessarily makes a big difference that makes their childhood mismatched and dissimilar to other kids.

\section{B. Partiality}

The ability to recover quickly from hardships and face them is common amongst middle children. Middle children experience difficulty finding a position of privilege and significance in the family because they never have the opportunity to monopolize parents' attention. Thus, they constantly fight to stay ahead of their younger siblings (Tam, C. L., \& Ha, T. S., 2011). Because they're not the firstborn or the youngest, middle children may feel like they need to compete for a parent's attention. They may feel overly jealous of their siblings and compete against them whenever possible (Fletcher, 2021). As a result, middle children tend to be more independent compared to their siblings as they are forced to quickly be mature and independent. For a child without immediate needs or perfected fit throwing skills, Middles need to think outside the box in order to achieve their own personal goals. This translates later in life with entrepreneurship, management abilities, persuasiveness, or even manipulation. Children stuck in the middle are able to play the field to their advantage (Kacillas, 2017). Studies also suggest that middle siblings are more impulsive, as well as more innovative than their older siblings, who are more likely to conform to the status quo (Sarolglou \& Fiasse, 2003; Saad, Gill, \& Nataraajan, 2005). There's a specific skill set that develops from being caught between two battle grounds and middle children are able to seize the opportunity. Middle children are more successful and rise to power better than first or last-born kids. It's a hard life, but that's why middle children turn out to handle hardship with grace and ease (Kacillas, 2017). Middle children not relying on their parents get molded at an early age. The partiality of the middle children allows them to be world-ready and more competent compared to their siblings.

\section{Timidity}

It is common within a family to have the eldest sibling carry most of the responsibilities and allocate most of the attention to the youngest child, leaving the middle children to have difficulties in finding their place in the family. Middle-children are believed to experience less interaction and receive less attention which negatively affects the self-esteem of the child (Jimoh, A.M., 2019). Furthermore, middle children, who have difficulty finding their place within their family and may feel squeezed in between their siblings, have a more difficult time developing feelings of belonging or social interest. Thus, they may also have more difficulty getting along or working with others (Gfroerer, $\mathrm{K}$ P., Gfroerer, C. A., Curlette, W. L., White, J. \& Kern, R. M., 2003). Middle children always feel inadequate since they constantly try to measure up to the accomplishments of their older siblings (Alder, A.). As a result, middle children often have quiet or dulled-down personalities, compared to their older and younger siblings. Since they fall somewhere in between their siblings, they are less likely to feel special or even equal to them (evolve treatment, 2020). However, if the middle child is the only boy or girl child in the family, he/she tends to hold a special status in the family, thereby providing a boost to self-esteem. (Henshaw, L., 2002). The lack of attention given to the middle children has severely affected their self-esteem as a result, middle children tend to grow up timid.

The experiences that middle children go through every day significantly impact their growth. Middle children, lacking the attention they need, are forced to mature at an early age, which benefits them as it makes them world-ready. However, the lack of attention within the family compromises their social skills, which negatively impacts their self-esteem.

\section{RESPONSIBILITY}

\section{A. Dissidence and Armistice}

Rivalry among siblings is inevitable but manageable in many ways. Each sibling has a role to play especially in peacemaking. The middle child is known to be expert peacemakers when there is a contest between them and because of this, they learn to read individuals and figure out what makes them tick. Because of their birth order, they are seen as mediators. When siblings are at brawl, often middle children are cooperative and understanding since they give importance to fairness (Gross, 2014). As the children in the middle, they are more willing to compromise so that they can argue successfully. Middle children are deemed to value fairness and equality since being the middle child of the family they know the feeling of being left out or overlooked. Growing up, middle children have always shared something with at least one of their siblings and this is the reason why they are great empaths and effective negotiators (Sternbergh, 2018). Hence, children in the middle have a strong social sense and are excellent team players. Let it be amongst their siblings or the people who surround them. Middle-borns are justice seekers and focus on fairness; they grew up with injustice so they practice what they preach. They see both sides of the stories and judge them well. 
with them making up for it and brushing it off as if nothing happened. After all, having a conflict among siblings is part of growing up with them and it also serves as lessons and memories to each of them.

\section{B. Perception on Studies}

Children in the middle are often overlooked because their efforts don't get enough attention. They are often overshadowed by the achievements of the first born and the needs of the last born. Thus leading the middle child to strive and work hard to avoid being missed out by their own parents or even relatives. Their desire to avoid being forgotten drives them to put effort into the things they do. Middle children are highly social, adaptable, and creative (Marcoux, 2017). As middle children rarely get their own way, they are skilled and savvy students. Consequently, they make it up to their perception on studies and academic activities (Griffin, 2012). Birth order aids in the development of talents that are essential in today's environment. They make great teachers, actors, social workers, and functional diplomats (Schumman, 2012). Middle children are often perceived as complacent and unassertive but when it comes to their perception on studies they fend for themselves. They are easily noticed by their parents when it comes to their academic achievements. In return, it becomes a win-win situation for both sides of the party involved.

They become skilled and smart manipulators since getting their way was uncommon. They have to work harder to overcome people's negative perceptions of them that makes them driven, charismatic, and smart.

\section{Duties}

In a family, as middle children and last-born children are aware of firstborns' higher status, they will try to set themselves apart from their siblings through alternative means. In terms of duties specifically in the house, middle children tend to get more tasks to be done because of certain conditions in the household or even favoritism. Middle children neither have any authority or responsible position like the eldest sibling nor do they receive any special attention from their parents and families like the youngest brother or sister (Pant, K., \& Singh, R., 2016). Alternatively, middle children may find it difficult to gain any privileged position or duties in the family because they were never able to capture their parents' attention (Tam, C. L., \& Ha, T. S., 2011). Hence, they are subjected to unfair responsibilities and roles by their parents. This affects their character formation especially when favoritism is seen. Because of this, middle children have nothing to make them feel special and worthy of themselves especially towards their parents thus, leading to the positive factor wherein middle children value fairness and justice in all aspects of their daily lives. At times, middle children act like the firstborn especially when there is a big age gap between them. In the absence of the firstborn, they fill in for the role that their sibling could not do (Marcoux, 2017).

Middle children are trustworthy and cooperative thus they find it very difficult to say no to duties and responsibilities that are laid out for them to do.

\section{AFFINITY}

\section{A. Consonance}

This study enlightens the common issues within a family and the solutions and coping mechanisms of the middle child to each issue. Though there are minor problems such as arguments that are common within a home that shelters a family, there are also major problems faced by the family themselves such as the barriers created between parents and the middle child. These barriers are either made by the parents' own actions, like work hours and comparing their generation to that of their children, or by circumstance, such as the death of a father at an early age of the child (Eisenberg, N., \& Valiente, C., 2002). Fahlberg (1991) revealed that there is evidence that the presence of siblings minimizes the trauma of parental separations or losses. A younger child spends nearly as much time interacting with older siblings as with the mother. Glover (2019) firmly believes that whatever the parents may have done to a child, his or her siblings are only rarely a part of the problem. However, it is not only the major problems that affect sibling relationships, it is also the little issues that creates some tension between the siblings. Brereton (2008) stated that it is important to keep into perspective that all sibling relationships include jealousy, bickering, squabbling, and sometimes battles. They all involve conflicting feelings of resentment and affection, embarrassment and pride, jealousy and companionship. The ways that each respondent deals with the aforementioned problems are a lot similar to how another deals with their own problems. Not only that, they also have to deal with the problems that their siblings bring. However, their tight-knit bonds come to light as they choose to overcome these problems together, leading to an agreement between the siblings (Scott, 2020). Thus, bringing a sense of consonance to the relationship of the middle child to their siblings.

\section{B. Acceptance}

Moreover, it is not all the time that middle children get in agreement with their siblings and deal with the problems with ease. The most common issue that middle children face is favoritism (Werner, 2013). Middle children generally don't feel that they are the favorite child of the family. Favoritism may exist for the oldest child who is viewed as special, or for the youngest child who is viewed as the baby. The middle child falls somewhere in-between and is unable to be the favorite of either parent (Davis, 2021). Despite these beliefs, the middle children learned how to accept that there is favoritism within the family. In fact, it is not an exclusive club reserved for only middle children, it is experienced by every child that has a sibling that outshines them in certain aspects of life. To Purohit's (2018) own observation, those who are talented, appear more attractive, and scored better marks in their academics are most likely to be the "chosen one" because of obvious reasons. Not only that, the middle children have accepted the fact that there would be favoritism at any point in their lives. Not only from their parents, but from any person, in any workplace, at any time (Collins, W. 1984). Acceptance is inevitable for middle children, but the way they embrace the garnered attention that is comparably lesser than their siblings are what makes them not part of the consensus. 


\section{Allegiance}

In the same manner, middle children have close relationships with their siblings, thus cultivating a harmonious relationship between siblings (Whiteman, S. D., McHale, S. M., \& Soli, A., 2011). Not only that, the relationships they have with their parents also contribute to making a positive and healthy environment around each other. Collins (1984) reveals that from the time when children enter school and the time they reach adolescence, the family plays a crucial role in socialization, although its role is not so predominant as in the early childhood years. In middle childhood, teachers, peers, coaches, and others outside the family have more contact with the child than in early childhood, and they exercise varying degrees of influence. During this time, parents negotiate on behalf of the child with these other socialization agents, but their parenting functions are still exercised mainly through interaction with the child. A relationship that a middle child exercises with his or her family creates a healthy environment. According to Smalley (1984), a close-knit family is full of people who are involved in each other's lives, who are aware of small and large events in each other's lives and are very supportive of each other in times of trouble. They may disagree about everything but still be very close-knit. The middle children clearly reveal that they are very close with their families, creating a close-knit family relationship that resonates love, security, and positivity.

Without a doubt, the relationships built by the middle children with his or her family has its significance on the life of the middle children. It will help them become more sociable, approachable, and friendly. It will transform them into better members of society. Yet most importantly, it also serves a greater purpose, as it greatly impacts the middle child's perception of the world, as he or she is able to see it in his or her own eyes without having a stereotype follow them around most of their life.

\section{CONCLUSION}

This research has established a foundation on which future research may be built. The demonstrated and discovered reality in the lived-experiences of Filipino middle children in Qatar spotlights that the way they are treated in the family according to their position imposes a major influence on the way they think and the way they respond to their decisions. There are a lot of common misconceptions and stereotypes amongst middle children. Middle children are perceived to be the timid, overshadowed, and peacemakers in the family; this is also called the "middle child syndrome". "The middle child syndrome is a belief that middle children are excluded, ignored, or even outright neglected because of their birth order (Adler, n.d.)." "Studies show that many middle children share common characteristics with each other, thus common ideas are formed around the middle children (Griffin, 2012)." At times, middle children have this feeling of unworthiness that may stem from the fact that their accomplishments, personality, and talents may be overshadowed by other family members. At the same time, they might find it hard to create and even maintain an intimate and close relationship with people who often devalue their existence. Based on the responses of the participants, these perceptions are deemed to be true to the majority but there are also a few participants who describe themselves as extroverted, appreciated, and not the peacemakers of the family. The participants also feel that they do not need to get their parents' attention, though some would strive to be great in terms of academics and extracurricular activities in order to garner attention. The consensus that middle children are more reserved, less extroverted, and more likely to face difficulties in socializing with other people including their parents are true to the majority of the participants.

This study pursues to create a summary on the contributing factors on the formation of identity of Filipino middle children here in Qatar. Maturity, Responsibility and affinity are all contributing factors in the formation of middle children's identity check. Components of the maturity factor consist of needing to be able to think more adultlike in order to be a good example to their younger siblings. Responsibility helps contribute to the formation due to the middle childrens need to play a role at home with their perception on studies, duties and armecities. The affinity factor shows the relationship of the child towards their parents and their siblings.

The findings highlighted in this study proves that middle children are sociable beings and highly effective despite the misconceptions and stereotypes being portrayed on them. This research has acted as a launching pad for subsequent research. The topics that emerged from this study show how maturity, responsibility, and affinity are factors that affect the identity formation of middle children. Middle children have a tendency to value fairness, to be understanding, cooperative, and adaptable while being competitive. Middle children, on average, do not excel in the same areas as their older siblings. Middle children's personality traits are frequently the polar opposite of their older and younger siblings. Because of their age and the amount of individual attention they have received from their parents, the second born is generally dominated by the firstborn, who is older, wiser, and more competent. Parents are frequently worn down and less likely to micro-manage by the time the second baby arrives. Because parents know their infant will not break, they may be more flexible with their attention and discipline. As a result, the second child learns to draw attention and entertain from an early age. Middle children, on the other hand, have a tendency to be understanding and conciliatory, whereas the oldest child is hardwired for greatness and achievement. Through these findings, schools, parents, and friends will be more aware of the misconceptions and stereotypes towards middle children.

\section{REFERENCES}

[1] Adler, A. (1930). Individual psychology. In C. Murchison (Ed.), International university series in psychology. Psychologies of 1930 (p. 395-405). Clark University Press. https://doi.org/10.1037/11017-021

[2] Arora, M. (2019). Middle Child Syndrome - Signs and Tips to Prevent It. Retrieved March 8, 2021, from https://parenting.firstcry.com/articles/middle-child-syndrome-signs-an d-tips-to-prevent-it/

[3] CSR- Center for Strategy Research Boston. (2006). "This is a recording"... Three Benefits of Recording Interviews. Research with a Twist. 2(5). Retrieved March 10, 2021, from https://csr-bos.com/this-is-a-recording-three-benefits-of-recording-inte rviews/ 
[4] Davis, B. (2021). Is the middle child the favorite? Retrieved November 17 , 2021,

from https://www.mvorganizing.org/is-the-middle-child-the-favorite/

[5] De Guzman, J. (2011). Family resilience and Filipino immigrant families: Navigating the adolescence life-stage. Retrieved March 14 2021,

from https://atrium.lib.uoguelph.ca/xmlui/bitstream/handle/10214/2806/The sis_FINAL_deGuzman.pdf?sequence $=1$

[6] de Guzman, A. B., Dalay, N. J. Z., De Guzman, A. J. M., de Jesus, L. L. E., de Mesa, J. B. C., \& Flores, J. D. D. (2009). Spirituality in Nursing: Filipino Elderly's Concept of, Distance from, and Involvement with God. Retrieved March 10, 2021, from https://eric.ed.gov/?id=EJ866382\#: :text=The\%20first $\% 20$ part $\% 20$ of $\% 20$ data,the $\% 20$ respondents' $\% 20$ concept $\% 20$ of $\% 20$ God.\&text $=$ The $\% 20$ study $\% 20$ has $\% 20$ eiditically $\% 20$ and,God $\% 20$ as $\% 20$ creating $\% 20$ and $\% 20$ creative.

[7] Dodgson, Lindsay. (2017). 'Middle child syndrome' doesn't actually exist - but it still might come with some surprising psychological advantages. Retrieved March 8, 2021, from https://www.businessinsider.com/middle-child-syndrome-psychologymyth-2017-1

[8] Draughn, A. (2016) The impact of psychological birth order on academic achievement and motivation. Walden Dissertations and Doctoral Studies. https://scholarworks.waldenu.edu/dissertations/2529

[9] Dworkin, S. (2012). Sample Size Policy for Qualitative Studies Using In-Depth Interviews. Retrieved March 10, 2021, from https://link.springer.com/article/10.1007/s10508-012-0016-6

[10] Eckstein, D. (2000). Empirical studies indicating significant birth-order-related personality differences. Retrieved November 20 , 2021, from The Journal of Individual Psychology

[11] Eisenberg, N., \& Valiente, C. (2002). Parenting and children's prosocial and moral development. Retrieved November 20, 2021

[12] Gabriel, D (2013). Inductive and deductive approaches to research. Retrieved March $\quad 9, \quad 2021$ from https://deborahgabriel.com/2013/03/17/inductive-and-deductive-appro aches-to-research/

[13] Gfroerer, K. P., Gfroerer, C. A., Curlette, W. L., White, J. \& Kern, R. M. (2003). Psychological birth order and the BASIS-A inventory. Retrieved November 20, 2021, from The Journal of Individual Psychology, 59, 30-41.

[14] Goudarzi, C. \& Goudarzi, S. (2019). Does birth order affect personality? Scientific American. Retrieved March 10, 2021, from https://www.scientificamerican.com/article/does-birth-order-affect-pe rsonality/

[15] Griffin, L. (2012). The Secret Powers of Middle Children. Retrieved March 8, 2021, from https://www.psychologytoday.com/us/blog/field-guide-families/20121 0/the-secret-powers-middle-children

[16] Ha, T. S., \& Tam, C. L. (2011). A Study of Birth Order, Academic Performance, and Personality. Retrieved November 20, 2021, from https://ipedr.com/vol5/no1/7-H00037.pdf

[17] Henshaw, L. (2002). A study of self-esteem in middle children. Theses and Dissertations. 1449. Retrieved March 16, 2021, from https://rdw.rowan.edu/etd/1449

[18] Imamura, T. (2010). Filipino Personality Traits and Values for Social Support: FOW as human resources for work life balance in Japan. 立正 大学心理学研究所紀要. 3(1), 1-16, Retrieved March 14, 2021, from https://researchmap.jp/read0040321/published_papers/16958044

[19] Jimoh, A. M. (2016). Impact of Birth Order and Emotional Intelligence on the Academic Performance of Secondary School students in Ibadan Oyo State. Nigerian Journal of Social Work Education. Retrieved November 20, 2021, from https://nigerianjournalofsocialworkeducation.com/wp-content/uploads /2019/06/IMPACT-OF-BIRTH-ORDER-AND-EMOTIONAL-INTE LLIGENCE-ON-THE-ACADEMIC-PERFORMANCE-OF-SECOND ARY-SCHOOL-STUDENTS-IN-IBADAN-OYO-STATE.pdf

[20] Kacillas, T. (2017, March 4). Middles don't give a S***. WeHaveKids. Retrieved November 20, 2021, from https://wehavekids.com/parenting/Middles-Dont-Give-a-S

[21] Lakritz, T. (2021, April 10). 'Middle child syndrome' is a myth. Here are 10 things you never knew about middle children. Retrieved November 20, 2021, from https://www.insider.com/middle-child-facts-2018-8\#they-have-a-good -chance-of-becoming-president-9

[22] Lester, S. (1999). An introduction to phenomenological research. Stan Lester Developments, Taunton. Retrieved March 16, 2021, from https://www.rgs.org/CMSPages/GetFile.aspx?nodeguid=7ad9b8d4-6a
93-4269-94d2-585983364b51\&lang=en-GB\#: :text=The\%20purpose $\% 20$ of\%20the \%20phenomenological,the \%20actors\%20in\%20a\%20si tuation.

[23] Marcoux, H. (2017). It's science. Middle children are more likely to be social and successful. Retrieved November 23, 2021, from https://www.mother.ly/life/its-science-middle-children-are-more-likel y-to-be-social-and-successful./

[24] MasterClass (2020). What Is Inductive Reasoning? Learn the Definition of Inductive Reasoning With Examples, Plus 6 Types of Inductive Reasoning. Retrieved March 9, 2021, from https://www.masterclass.com/articles/what-is-inductive-reasoning\#wh at-is-inductive-reasoning

[25] Miralao V. (1997). The Family, Traditional Values and the Sociocultural Transformation of Philippine Society. Philippine Sociological Review, 45(1/4), 189-215. Retrieved March 16, 2021 from http://www.jstor.org/stable/41853694

[26] Mustafa, A. (2021). Phenomenological Study. Retrieved March 9, 2021 ,

https://www.academia.edu/41976162/Phenomenological_Study

[27] Pathak, V. (2017). Phenomenological Research: A Study of Lived Experiences, 3(1), 1719. Retrieved March 9, 2021, from minUploadPdf/Phenomenological_Rehttp://ijariie.com/Adsearch_A_ Study_of_Lived_Experiences_ijariie3960.pdf

[28] Pant, K., \& Singh, R. (06 2016). Understanding Social and Emotional Maturity of Adolescents: Analysing Impact of Birth Order. International Journal of Humanities and Social Sciences (ISSN Print:2319-393X Online: 2319-3948), 5, 221-230.

[29] Saad, G., Gill, T., Nataraajan, R. (2005). Are laterborns more innovative and nonconforming consumers than firstborns? Retrieved November 20, 2021, from A Darwinian perspective. Journal of Business Research, 58, 902- 909

[30] Salmon, C., \& Schumann K. (2011). The Secret Power of Middle Children. Retrieved March 23, 2021 from http://www.thesecretpowerofmiddlechildren.com/

[31] Saroglou, V., \& Fiasse, L. (2003). Birth order, personality, and religion: a study among young adults from a three-sibling family. Personality and Individual Differences, 35(1), 19-29. https://doi.org/10.1016/s0191-8869(02)00137-x

[32] Scroope, Chara. (2016). Filipino Culture. Retrieved March 8, 2021 from

https://culturalatlas.sbs.com.au/filipino-culture/filipino-culture-family \#filipino-culture-family

[33] Whiteman, S. D., McHale, S. M., \& Soli, A. (2011). Theoretical perspectives on sibling relationships. Retrieved November 19, 2021

[34] Werner, C. (2013). Birth Order and Personality: The Science Behind Middle Child Syndrome. Retrieved March 8, 2021, from https://www.healthline.com/health/mental-health/middle-child-syndro me

[35] Wong, L. P. (2008). Data analysis in qualitative research: a brief guide to using Nvivo. Malays. Fam. Phys 2008; (3)1: 14-20. Retrieved March 10, 2021, from https://www.ncbi.nlm.nih.gov/pmc/articles/PMC4267019/

[36] Yael Klein. (2020). Is middle child syndrome real?. Evolve Treatment Centers. Retrieved November 25, 2021, from https://evolvetreatment.com/blog/middle-child-syndrome/ 